\title{
Los distritos urbanos gastronómico- turísticos, conflictos y problemas de gestión pública. Guadalajara, México
}

Basilio Verduzco. Universidad de Guadalajara, Guadalajara, México.
Basilia Valenzuela. Universidad de Guadalajara, Guadalajara, México.

RESUMEN | La transformación de áreas centrales residenciales en distritos gastronómico-turísticos es parte de un proceso de cambio que plantea retos de planificación urbana y de gestión de conflictos. Para ser competitivas, las ciudades escenifican el espacio urbano como un lugar donde los turistas pueden coproducir sus experiencias de viaje. Los destinos turísticos urbanos son representados como espacios seguros, abiertos a la inversión y a la innovación de bienes y servicios. El ensayo analiza el fenómeno de la formación de distritos urbanos gastronómico-turísticos (DUGT) como parte de la transformación de grandes ciudades. Se estudian dos zonas residenciales en Guadalajara, Jalisco, como espacios de conflictos de intereses entre grupos de altos ingresos similares a los derivados de procesos de gentrificación. Se identifican retos de política pública y para procesos de negociación dirigidos a resolver las controversias asociadas a la procuración de una mejor posición de la ciudad en el mapa económico mundial.

PALABRAS CLAVE | gentrificación, gestión urbana, conflicto social.

ABSTRACT | The transformation of residential central areas into urban tourist and gastronomic destinations, is part of a larger process which poses important challenges for urban management and social conflict resolution. To be competitive, cities stage urban space as a place where tourists may co-produce travel experiences. Urban tourist destinations are represented as safe spaces, open to investment and to product and service innovation. This essay analyzes the emergence of Gastronomy-Tourism Urban Districts (DUGTs) as a common process in large scale cities. It looks at the transformation of two residential areas in the city of Guadalajara, Jalisco, as spaces for conflicts of interests among high income groups, which are similar to those associated with gentrification. The paper identifies challenges for public policy and for negotiation processes aimed at solving controversies associated to the search for a better position for cities in the global economic map.

KEYWORDs | gentrification, urban management, social conflict. 


\section{Introducción}

La transformación del espacio urbano de grandes ciudades para fines gastronómicos y turísticos es un problema de gestión pública con ramificaciones en los campos de planeación urbana, gestión de conflictos y negociación. Los distritos urbanos gastronómicos turísticos (DUGT) conforman un ecosistema urbanístico, turístico, social y económico comercializable como lugar para vivir experiencias de viaje memorables y auténticas, como el consumo de comidas locales (Okumus, Okumus \& McKercher, 2007). Con ellos se puede diversificar la oferta de productos turísticos (Benur \& Bramwell, 2015). Cada DugT sigue un proceso de escenificación para experiencias turísticas y cuenta como intento de revitalización de la ciudad (Crespi \& Domínguez, 2013) o como paso hacia la mercantilización del espacio urbano (Hall \& Gossling, 2016). La transformación puede asociarse al desarrollo de marcas gastronómicas regionales (Gordin \& Trabskaya, 2013) o al rescate de patrimonios culinarios (Kowalczyk, 2014). A veces la escenificación turística conduce a la festivalización del espacio urbano (Richards, 2002). El éxito de los distritos depende de factores como capacidad de innovación, calidad de los servicios, mercadotecnia y la capacidad de gestión pública y de manejo de controversias. Las ciudades tienen éxito en la creación de DUGT si logran procesos de negociación multilateral que resulten en consensos.

Dos corrientes de literatura ayudan a entender este fenómeno. Primero, los estudios sobre conformación de cascos o distritos gastronómicos como sistemas locales de turismo (Lazzaretti \& Petrillo, 2006); distritos regionales que integran producción y procesamiento de alimentos moldeados por relaciones de competencia y colaboración (Barrére, Quentin \& Chossat, 2012); cascos urbanos y diseños relacionados con lo social (Perham, 2012); procesos de gentrificación simbólica (Vergara-Constela \& Casellas, 2016); o formación de distritos creativos (Thomasz, 2016). Segundo, la literatura sobre gestión de conflictos que enfatiza la necesidad de analizar los involucrados y los asuntos sujetos a negociación (Byrd, 2007; Ellis \& Sheridan, 2014; Medeiros de Araujo \& Bromwell, 2000; Modica, 2015; Ruzzier \& Petek, 2014; Verduzco, 2013). Esta literatura da cuenta de factores como participación previa de involucrados en conflictos, experiencia de liderazgo, o aspectos de la dinámica socioespacial. En ella se reconocen la influencia de aspectos locales como el medioambiente urbano, el estado de las infraestructuras urbanas y la existencia de oportunidades de participación sociopolítica; o aspectos internacionales como la posición de la ciudad en el comercio internacional, los flujos de inversión extranjera directa y de turismo y la experiencia con fenómenos migratorios y su impacto en la oferta gastronómica.

Este ensayo analiza la transformación que tiene lugar en dos zonas residenciales de altos ingresos en Guadalajara, Jalisco, una ciudad con origen colonial ubicada en el occidente de México, cuya zona metropolitana tiene alrededor de cinco millones de habitantes. 


\section{Conflictos sociourbanos y creación de distritos urbanos gastronómico-turísticos}

La formación de DUGT es un fenómeno de la ciudad contemporánea que aspira a ocupar un lugar en el escenario económico mundial (Jensen-Verbeke \& Govers, 2009; Kong \& Sinha, 2016). Su gestación forma parte de procesos de reconversión productiva, especulación inmobiliaria y procesos de desigualdad social urbana. Son promovidos por alianzas formales o informales que procuran la competitividad internacional de las ciudades y por gobiernos locales que responden a grupos de interés y segmentos privilegiados del electorado local. No hay consenso sobre el concepto de DUGT, pero rescatando principios de economía urbana y de propuestas recientes sobre el advenimiento de la economía de la experiencia (Pine \& Gilmore, 1999), es posible una delimitación para el análisis empírico:

a. Aglomeración espacial de unidades económicas complementarias (hoteles, restaurantes, museos, tiendas de artesanías, centros comerciales, etcétera) que ayudan a los turistas a coproducir sus experiencias (Lazzaretti \& Petrillo, 2006) mediante el trazo de rutas lo suficientemente atractivas y cortas para realizar varios recorridos peatonales.

b. Grandes proyectos culturales o inmobiliarios de uso mixto (vivienda, comercio y oficinas) que sirven como anclas de la dinámica urbana, económica y social de los distritos en cuestión.

c. Identidad o herencia barrial o distrital preexistente (casco cultural), usualmente definida en torno al nombre de un equipamiento, una calle, una colonia o algún otro referente cultural o sociourbano que permite establecer un vínculo entre pasado y futuro del distrito (Barrére et al., 2012; Hall \& Gossling, 2016).

El DUGT es una organización sociourbana construida para facilitar la mercadotecnia territorial y la organización de la oferta de servicios al turista en un contexto socialmente diverso y urbanísticamente atractivo. Su formación es un fenómeno de finales del siglo $\mathrm{xx}$, pero se ha extendido a las principales ciudades del mundo. A pesar de los éxitos reconocidos y celebrados a nivel internacional, los DUGT constituyen una estrategia no exenta de conflictos, que se manifiestan de múltiples maneras: como confrontación entre grandes desarrolladores inmobiliarios y vecinos; nuevos inversionistas $v s$. pequeños inversionistas locales; y promoventes de proyectos $v s$. activistas ambientales $\mathrm{u}$ organizaciones comunitarias interesadas en preservar la imagen urbana, la cultura local o el patrimonio urbano. A veces son batallas legislativas entre actores privados y funcionarios públicos; enfrentamientos entre vecinos y empresas promotoras de proyectos considerados indeseables en el patio trasero de un vecindario, o NIMBY, como son conocidos en la literatura anglosajona (Gibson, 2012; Van der Aa, Groote \& Huigen, 2004); o bien como oposición vecinal a proyectos de redensificación y expansión comercial en suburbios metropolitanos donde se enfrenta la dificultad de encontrar el balance adecuado entre uso de suelo, y estándares que satisfagan las necesidades y valores de la comunidad (Arnold, 2016). 
La consolidación de un DUGT confronta los intereses colectivos, expresados en la protección del espacio y la convivencia pública, y los intereses privados (GravariBarbas \& Jacquot, 2017). La escenificación turística en un DUGT y la gentrificación comparten la generación de consecuencias adversas. En ambos procesos, la presencia de usuarios de ingresos cada vez más altos conlleva el desplazamiento de habitantes y usuarios con ingresos menores (Fox, 2010; Lees, 2000; Wilson \& Tallon, 2012). Ambos procesos introducen cambios radicales en el paisaje urbano, generan congestionamiento de vías de comunicación e infraestructura y, a menudo, pérdida de patrimonio urbano y natural de las ciudades (Della Lucia, Trunfio \& Go, 2016; Lew, 2007). El Estado suele apoyar estos procesos resaltando los beneficios para la economía (Rogerson, 2006): empleos en la industria de construcción, nuevos empleos en comercio y turismo, posicionamiento de la ciudad como centro internacional de negocios y, en general, contribuciones a la competitividad turística y urbana en un contexto posindustrial (Tallon, 2013). La conformación de DUGT no necesariamente resulta en conflicto entre clases sociales. Los DUGT formados en barrios de clase media y alta no implican los típicos enfrentamientos de clases o el desplazamiento de pobres por nuevos pobladores reportados en el enfoque revanchista de la gentrificación (Glass, 2010; Lees, 2000; Smith, 1996); más bien, dan lugar a conflictos en torno a la preservación de estilos de vida y a disputas por beneficios del proceso de cambio.

\section{El distrito urbano gastronómico-turístico como fenómeno de grandes ciudades}

La creación de DUGT es un fenómeno que puede tener lugar a nivel de regiones (Boyd, 2015), pequeños centros de población (Leal, 2015), como son, en México, San Cristóbal de las Casas, Chiapas; Puerto Nuevo en Baja California; la Quinta Avenida en Playa del Carmen y Quintana Roo, o el centro de San Miguel de Allende en Guanajuato. Sin embargo, su verdadera vocación es servir como pilar de los esfuerzos de diversificación del producto turístico en grandes ciudades.

En Estados Unidos, las grandes zonas metropolitanas han impulsado esta estrategia a distintas escalas. Gaslamp como distrito de alcance metropolitano en San Diego, California; Chelsea o soHo en Nueva York; o pequeñas zonas de alimentos en suburbios metropolitanos. Otros casos destacados a nivel internacional son Xintiandi en Shanghai, La Condesa en la Ciudad de México, Puerto Madero en Buenos Aires o Bellavista en Santiago de Chile. Estas transformaciones tienen varios elementos en común y son impulsadas en forma colectiva (Corvo, 2015). Los aspectos considerados indispensables para el éxito de un DUGT son:

a. Fuerte inversión pública en proyectos de infraestructura urbana y equipamiento.

b. Grandes proyectos inmobiliarios que combinan usos de oficinas, comercios y usos mixtos con soluciones de vivienda vertical de altos ingresos.

c. Renovación constante de imagen urbana a partir de la adición y/o remplazo de mobiliario urbano, y regulación de la edificación, la imagen urbana y los usos de suelo. 
d. Énfasis en la promoción de una orientación festivo-comercial-cultural dirigida a consumidores de altos ingresos que buscan entretenimiento y gastronomía diversificada.

e. Desarrollos inmobiliarios que rescatan parcialmente tradiciones urbanas locales y procuran encontrar un lugar en el urbanismo global.

f. Edificaciones de uso mixto que convocan a nuevos consumidores, familias jóvenes y turistas a forjar experiencias vivenciales y de viaje en torno al consumo suntuario y efímero.

g. Incorporación de distintos, pero notorios, grados de seguridad privada para suplir las deficiencias del Estado como proveedor de ese bien público.

h. Celebración de eventos de tipo turístico cultural diseñados como espacios de convivencia social y oportunidades de posicionamiento regional, nacional e internacional de estas zonas en tanto nuevos productos turísticos en una ciudad.

i. Segregación interna en el uso de los espacios para atender las capacidades de ingreso diferenciadas entre los públicos objetivo.

j. Soluciones urbanísticas dirigidas a inducir comportamientos, desalentar a visitantes no deseados, y otras que apuntan a resaltar el poder icónico de estas zonas dentro del contexto urbano metropolitano e internacional.

En Guadalajara, con una población metropolitana estimada en 2010 de 4.434 .878 habitantes (Secretaría de Desarrollo Social [Sedesol], Consejo Nacional de Población [Conapo] \& Instituto Nacional de Estadística y Geografía [Inegi], 2012), se tienen ubicados cuatro distritos que se aproximan al concepto de DUGT propuesto: el triángulo Plaza del Sol-Chapalita-Expo Guadalajara (centro-sur), el distrito Chapultepec (centro-poniente), el centro de Tlaquepaque (oriente) y el distrito de Providencia (noroeste). Extrapolando ese dato a nivel nacional, y dada la existencia de 59 zonas metropolitanas formadas por 367 delegaciones o municipios en donde viven 63,8 millones de personas (Sedesol, Conapo \& Inegi, 2012), el potencial de la existencia de DUGT oscila entre 59 y 64 para contar con un distrito por cada millón de habitantes y alrededor de 400 si cada municipio metropolitano tuviera por lo menos uno.

La selección de Chapultepec y Providencia permite analizar el proceso de escenificación urbana gastronómico-turística en zonas habitacionales de ingresos medios y altos como un fenómeno controversial. Los casos ilustran la formación de DUGT en el contexto de la emergencia de nuevos estilos de vida urbana, nuevas estructuras familiares, la nueva orientación del turismo hacia la búsqueda de experiencias turísticas y la incursión de nuevos modelos de valorización urbana con dividendos para alianzas pro crecimiento y su influencia en la política urbana. Después de una breve contextualización de los casos en la metrópoli, se hace un análisis comparado atendiendo a tres aspectos de su perfil urbano y cuatro aspectos de los conflictos y discursos asociados a la escenificación de los distritos gastronómicos. 


\section{Chapultepec y Providencia en el contexto metropolitano de Guadalajara}

Chapultepec y Providencia son parte del municipio de Guadalajara, capital de Jalisco y ciudad central de una zona metropolitana formada por nueve municipios (tabla 1). Los distritos no tienen límites territoriales claramente definidos, pero son referentes difusos para especulación inmobiliaria, mercadotecnia territorial y formación de identidades barriales (Mariscal, 2015). La definición territorial empleada aquí no es usada como tal en políticas de promoción de turismo o en planes, proyectos y programación de eventos; de hecho, aunque el Plan de Desarrollo Municipal de Guadalajara considera el turismo una actividad estratégica, no identifica zonas especiales (H. Ayuntamiento de Guadalajara, 2016).

En estos DUGT hay un proceso de escenificación urbana gastronómico-turística similar a la transición reciente de barrios previamente gentrificados en ciudades como Nueva York o Londres (Lees, 2000). Este fenómeno es posible en ciudades como Guadalajara gracias a la influencia de la globalización, la desigualdad urbana imperante y el peso del turismo en la economía de estas ciudades (Janoschka, Sequera \& Salinas, 2014). El proceso de escenificación enfrenta a viejos y nuevos pobladores: usuarios del espacio urbano para la reproducción familiar y grupos sociales que buscan "seguir viviendo en la ciudad", entretenimiento y experiencias turísticas; desarrolladores inmobiliarios que buscan lavar dinero y/o acumular fortunas; y grupos opositores que están a favor de la preservación urbana y el cuidado ambiental y del patrimonio.

Los distritos se ubican al poniente de la ciudad (figura 1). ${ }^{1}$ Surgieron como barrios residenciales periféricos y son producto de procesos de intervención pública y especulación urbana. Su construcción sirvió para mantener viva la segregación socioespacial oriente-poniente que ha caracterizado a Guadalajara desde su fundación en 1542. Sin embargo Chapultepec y Providencia han registrado procesos históricos de desarrollo urbano y comercial distintos.

La tabla 1 muestra la importancia relativa de la oferta gastronómica y de hotelería de los distritos estudiados a inicios de 2016. Chapultepec tenía 602 unidades económicas, que representan el 2,41\% del total de la Zona Metropolitana de Guadalajara (ZMG), y el 5,25\% de la oferta en el municipio de Guadalajara. Providencia tenía 259 unidades que representan el 1,04\% y 2,26\%, respectivamente.

TABLA I Unidades económicas de alimentos y hospedaje en Chapultepec y Providencia

\begin{tabular}{|l|c|c|c|}
\hline \multirow{2}{*}{\multicolumn{1}{c|}{ UNIDAD TERRITORIAL }} & \multicolumn{3}{|c|}{ UNIDADES ECONÓMICAS } \\
\cline { 2 - 4 } & TOTAL & \% RESPECTO A ZMG & $\begin{array}{c}\text { \% RESPECTO A } \\
\text { GUADALAJARA }\end{array}$ \\
\hline Jalisco & 42.903 & 172,43 & 374,73 \\
\hline ZMG (9 municipios) & 24.882 & 100,00 & 217,33 \\
\hline Guadalajara & 11.449 & 46,01 & 100,00 \\
\hline Ixtlahuacán de los Membrillos & 105 & 0,42 & 0,92 \\
\hline
\end{tabular}

1 Los autores agradecen el apoyo de Álvaro Mora en la preparación de figuras. 
(continuación)

\begin{tabular}{|l|c|c|c|}
\hline \multirow{2}{*}{\multicolumn{1}{c|}{ UNIDAD TERRITORIAL }} & \multicolumn{3}{|c|}{ UNIDADES ECONÓMICAS } \\
\cline { 2 - 4 } & TOTAL & \% RESPECTO A ZMG & $\begin{array}{c}\text { \% RESPECTO A } \\
\text { GUADALAJARA }\end{array}$ \\
\hline Juanacatlán & 92 & 0,37 & 0,80 \\
\hline El Salto & 707 & 2,84 & 6,18 \\
\hline Tlajomulco de Zúniga & 1.585 & 6,37 & 13,84 \\
\hline San Pedro Tlaquepaque & 2.544 & 10,22 & 22,22 \\
\hline Tonalá & 1.979 & 7,95 & 17,29 \\
\hline Zapopan & 6.083 & 24,45 & 53,13 \\
\hline Zapotlanejo & 338 & 1,36 & 2,95 \\
\hline Total DGUT-Providencia & $\mathbf{2 5 9}$ & $\mathbf{1 , 0 4}$ & $\mathbf{2 , 2 6}$ \\
\hline Total DGUT-Chapultepec & $\mathbf{6 0 2}$ & $\mathbf{2 , 4 2}$ & $\mathbf{5 , 2 6}$ \\
\hline
\end{tabular}

FUENTE ELABORACIÓN PROPIA CON DATOS DE INSTITUTO NACIONAL DE ESTADÍSTICA Y GEOGRAFÍA (INEGI), DIRECTORIO ESTADÍSTICO NACIONAL DE UNIDADES ECONÓMICAS (DENUE), ENERO DE 2016

La figura 2 presenta un análisis comparado de indicadores básicos de ambos distritos definidos como grupos de las Áreas Geo-Estadísticas Básicas (AGEB), comúnmente asociadas a las marcas Chapultepec y Providencia. Con sus 9.946 y 27.930 habitantes en 2010, Chapultepec y Providencia representaban una mínima proporción de la población del municipio de Guadalajara: 0,67\% para Chapultepec y 1,87\% para Providencia. Ambas zonas tienen el objetivo de atraer a la población de otras partes de la ciudad y a visitantes nacionales y extranjeros. Ambos distritos tienen proporcionalmente menos población de entre 18 y 24 años que el municipio de Guadalajara y más población de la tercera edad (1,13\% y 3,23 \% para Chapultepec y Providencia, respectivamente).

Chapultepec y Providencia presentan niveles de educación más altos que el resto del municipio (entre 1,32 y 1,4 años por cada año en el municipio); un tamaño promedio de familia sustancialmente menor $(0,71$ y 0,73 habitantes por habitante del municipio,) y tienen proporcionalmente más población nacida en otra entidad, lo que refleja su poder de atraer a población migrante de ingresos altos. 
FIGURA I Localización de los distritos urbanos gastronómico-turísticos en Guadalajara, Jalisco, México

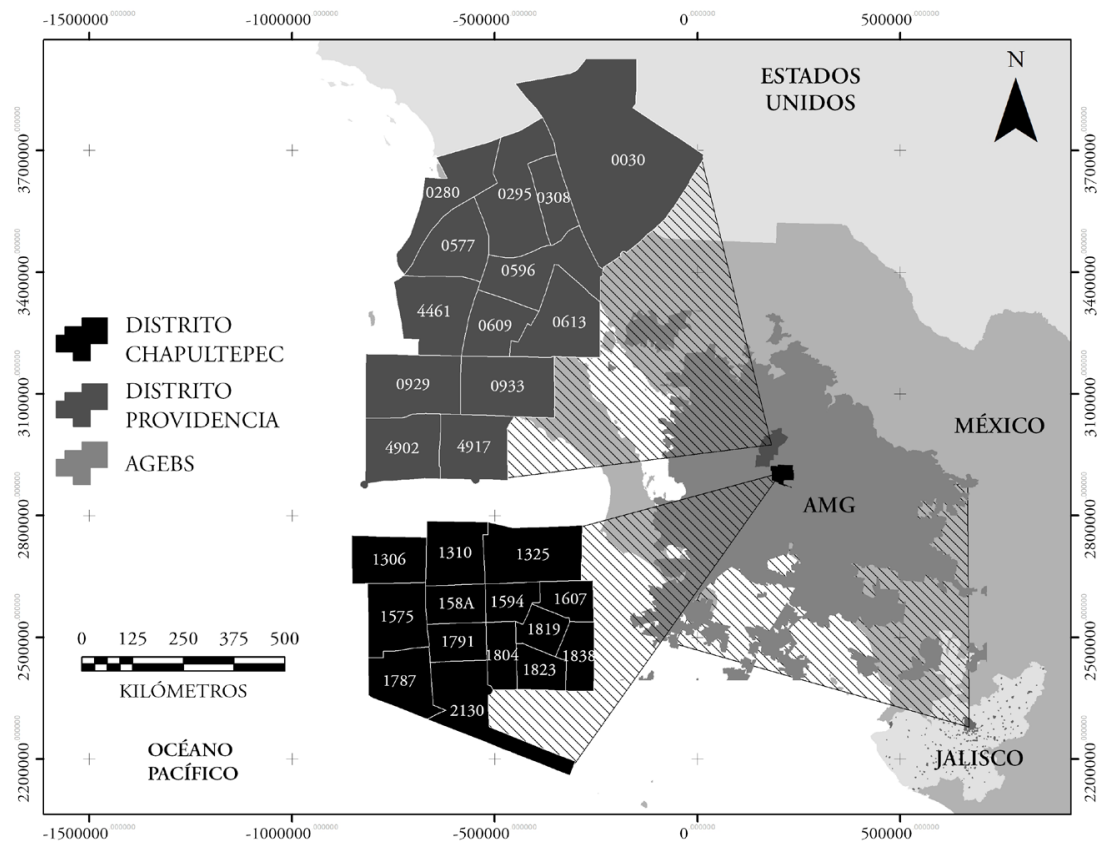

FUENTE ELABORACIÓN PROPIA CON DATOS DE INSTITUTO NACIONAL DE ESTADÍSTICA Y GEOGRAFÍA (INEGI), DIRECTORIO ESTADÍSTICO NACIONAL DE UNIDADES ECONÓMICAS (DENUE), ENERO DE 2016

FIGURA 2 | Indicadores sociodemográficos básicos por distrito (2010)

"DUGT-Chapultepec $\quad$ DUGT-Providencia

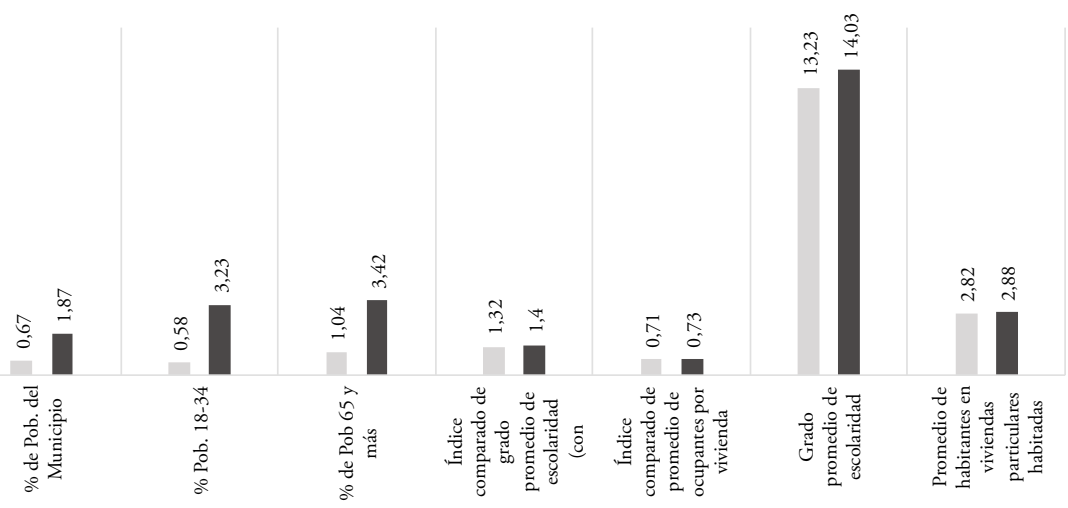

FUENTE ELABORACIÓN PROPIA CON DATOS DE INSTITUTO NACIONAL DE ESTADÍSTICA Y GEOGRAFÍA (INEGI) (2OI I), XIII CENSO GENERAL DE POBLACIÓN Y VIVIENDA 2010 


\section{Perfil urbano de los distritos}

\section{Perfil urbano del DUGT-Chapultepec}

a. Orígenes y delimitación. El Distrito Urbano Gastronómico-Turístico de Chapultepec (DUGT-CH) abarca aproximadamente 200 manzanas en las zonas aledañas a la avenida Chapultepec, con una longitud aproximada de 1,4 km, extendidas de sur a norte. Este distrito surgió y se consolidó como zona habitacional de altos ingresos en las primeras décadas del siglo xx. Una parte de este polígono surgió en 1914 con el nombre de Colonia Obrera como una de las primeras intervenciones públicas en vivienda. Otra parte corresponde a la Colonia Americana, que data de la primera década del siglo xx, y otra a la Colonia Francesa (López, 2001), las cuales atrajeron a pobladores de altos ingresos. Todo el polígono fue diseñado con buenas vialidades para permitir el flujo desde el centro de la ciudad hacia las salidas del sur y del poniente.

b. Valor histórico y patrimonial. Sin contar con la herencia arquitectónica colonial del centro de Guadalajara, el DUGT-CH tiene un importante valor patrimonial arquitectónico. Para 1942, cuando la ciudad estaba celebrando cuatrocientos años de su fundación, Chapultepec era un espacio urbanísticamente consolidado. Muchas de sus residencias fueron construidas por arquitectos que ganaron fama nacional e internacional, como Luis Barragán, Pedro Castellanos, Pedro Ursúa y Julio de la Peña. Este polígono se consolidó como lugar de residencia de familias de altos ingresos durante el auge registrado en la ciudad después de la Segunda Guerra Mundial.

c. Experiencia previa de desarrollo comercial. Sin perder sus usos habitacionales, el distrito fue ganando importancia y centralidad comercial durante las últimas tres décadas del siglo xx debido al crecimiento suburbano registrado al poniente y sur de la ciudad. Aquí tenía su sede la Cámara de Comercio de Guadalajara. La transición a distrito gastronómico se inició en la década de los noventa de la mano de sucesivas intervenciones urbanísticas e inversiones públicas y privadas, como el restaurante abierto en 1995, que ofrecía la experiencia del buen comer en un ambiente del viejo oeste americano, para "hombres de empresa, de negocios y de las familias de todas las clases sociales" ("Acercan más servicios...", 8 de mayo de 1995), o la librería del Fondo de Cultura Económica, casa editorial del gobierno federal, inaugurada en 1999.

\section{Perfil urbano del DUGT-Providencia}

a. Orígenes y delimitación. El Distrito Urbano Gastronómico-Turístico de Providencia (DUGT-P) ejemplifica la aspiración de las ciudades de ocupar un lugar en el escenario global. Intervenciones públicas y privadas comparten dicha aspiración y han logrado cambiar el perfil suburbano residencial del barrio para convertirlo en escenario de una fuerte especulación inmobiliaria y densificación. Este distrito abarca un polígono con una extensión de norte a sur de aproximadamente $3,5 \mathrm{~km}$. Tiene orígenes más recientes y es producto de la ola expansiva de suburbanización registrada en Guadalajara a finales de la década de los sesenta y setenta del siglo xx. 
b. Valor histórico y patrimonial. En Providencia no se tiene reconocimiento de fincas con valor patrimonial. Dado el perfil de las colonias que lo forman, orientadas a familias suburbanas de altos ingresos, los desarrolladores usaron modelos relativamente estandarizados de edificación similares a suburbios de Estados Unidos y ofrecieron un producto netamente habitacional de baja densidad con amplias avenidas, camellones ajardinados, calles secundarias de tres carriles, parques públicos y tamańos mínimos de lote relativamente grandes para viviendas unifamiliares de uno o dos pisos con amplios jardines. Algunas de sus casas reproducen el estilo arquitectónico californiano de la segunda mitad del siglo xx y cuentan con albercas o canchas de tenis o frontón. El modelo atrajo a pobladores locales y a familias de la región, que vieron en este fraccionamiento una buena oportunidad para dar seguridad a sus capitales acumulados en pueblos del Estado y ciudades vecinas. ${ }^{2}$

c. Experiencia previa de desarrollo comercial. Los dos antecedentes comerciales de Providencia son, primero, la provisión de bienes de consumo esenciales para la vida suburbana de las familias: seguridad, tiendas de abarrote y la evolución a supermercados, farmacias, ferreterías, papelerías, etcétera, alrededor de la principal iglesia católica del barrio, que configuraron un corredor comercial incipiente en los cruces de las avenidas Terranova-Providencia/Pablo Neruda; y segundo, la transformación de los usos habitacionales de ambos lados de la avenida Américas, en un tramo cercano al Club de Golf, que desde los 1980 empezó a transformarse en corredor financiero, con la construcción de sedes bancarias y oficinas corporativas.

\section{Conflictos en torno a la escenificación turística de Chapultepec y Providencia}

La formación de los DUGT Chapultepec y Providencia es fuente de conflictos sociourbanos y genera nuevos discursos sobre el proceso de desarrollo urbano. Una breve caracterización de este fenómeno en ambos distritos ilustra la naturaleza de dichos conflictos, y la magnitud de los retos de negociación y gestión urbana que representan.

\section{Un horizonte conflictivo en Chapultepec}

a. Proceso de conversión en distrito gastronómico. La transformación del DUGT-Chapultepec ha sido un largo proceso en el que terratenientes y gobiernos locales concluyeron que era necesario cambiar la imagen del distrito. Los gobiernos locales han facilitado la instalación de bares, restaurantes y hoteles, y han ejecutado obras públicas sobre toda la avenida Chapultepec y tramos de las calles que la cruzan. En este distrito se pueden distinguir tres secciones que fungen como anclas que orientan los flujos peatonales y la construcción de experiencias turísticas: (i) el corredor López Cotilla, (ii) la sección centro-norte de la avenida Chapultepec que va de su cruce con la avenida La Paz y la manzana donde se 
encuentra el recientemente creado Mercado México, y (iii) la parte sur de la avenida donde se localiza el proyecto Horizontes Chapultepec (figura 3).

Para estimar la densidad de establecimientos ${ }^{3}$ en las AGEB que conforman este distrito, se usa información del Directorio Estadístico Nacional de Unidades Económicas (Denue) y la cartografía del Instituto Nacional de Estadística y Geografía (Inegi). La figura 4 muestra tres densidades distribuidas de la siguiente manera: alta, en las AGEB de la zona centro-norte que convergen sobre la avenida Chapultepec; media, en la zona oriente y sur-poniente que incluye la AGEB 2130; y baja, en la parte sur-oriente correspondiente a la AGEB 1787. En este distrito se puede ver la ola expansiva de conversión a distrito gastronómico que tiene su epicentro en la avenida Chapultepec y el corredor López Cotilla.

b. Propuestas de transformación de las administraciones locales. Los cambios de imagen de este distrito se deben a sucesivas olas de remodelación realizadas por cinco administraciones municipales emanadas del Partido de Acción Nacional (1995-2009), tres del Partido Revolucionario Institucional (2009-2015) y la más reciente del Partido Movimiento Ciudadano (2015-2018). Las políticas dominantes son la aprobación de planes parciales de desarrollo urbano con criterios de zonificación para permitir mayor intensidad de urbanización y la proliferación de negocios gastronómico-turísticos; y la inversión pública directa en oficinas o en obras de renovación de imagen y mejoramiento de infraestructuras viales. Tanto el gobierno municipal como el estatal han hecho inversiones dirigidas a facilitar la transformación de este distrito.

Desde 1995 se discutían nuevos planes de desarrollo urbano. Los planes aprobados en 2003 contemplaban un corredor de uso mixto distrital a lo largo de las avenidas Chapultepec, La Paz (H. Ayuntamiento, 2001-2003a), Vallarta, Hidalgo y México (H. Ayuntamiento, 2001-2003b); y mixto barrial, en todas las zonas aledañas a la avenida Chapultepec. A finales del año 2000, el gobierno municipal anunciaba tener un proyecto consensuado de peatonalización de avenida Chapultepec ("En el Centro histórico...", 25 de octubre de 2000). Desde entonces, se han remodelado banquetas, remplazado las instalaciones sanitarias, instalado concreto estampado sobre toda la avenida Chapultepec y, recientemente, en la calle López Cotilla, se ha hecho una intervención para convertirla en zona 30 con ciclovía. En el DUGT-CH se organizan diversos eventos festivo-culturales que crean una oferta pública de entretenimiento, complementaria a la existente en los bares y centros de entretenimiento privados. El camellón central de avenida Chapultepec ha sido intervenido para fungir como paseo peatonal similar a Las Ramblas de Barcelona, España. Aquí se organizan exposiciones culturales, ferias artesanales, agrícolas y manifestaciones audiovisuales; y en López Cotilla y sus alrededores se promueve el concepto de experiencia gastronómica bajo el tema "Saborea Guadalajara". 
FIGURA 3 | Distribución de establecimientos gastronómico-turísticos en el DUGT-Chapultepec

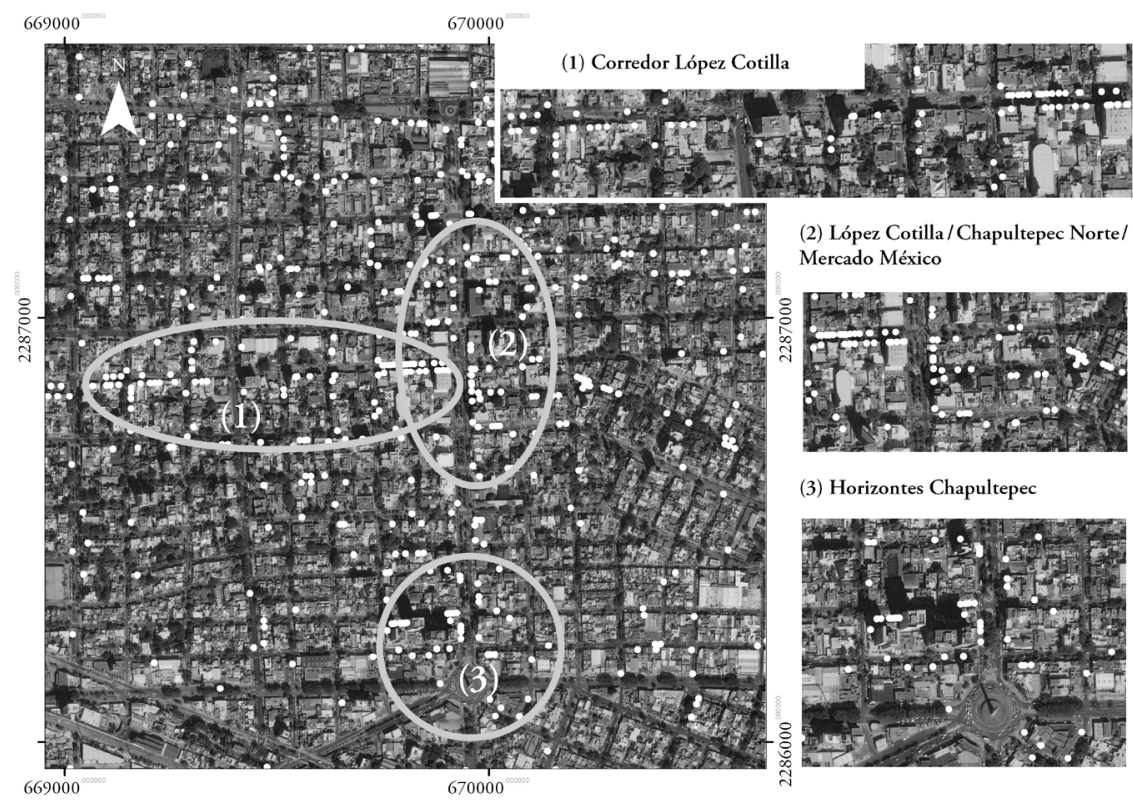

FUENTE ELABORACIÓN PROPIA CON DATOS DE INSTITUTO NACIONAL DE ESTADÍSTICA Y GEOGRAFÍA (INEGI), DIRECTORIO ESTADÍSTICO NACIONAL DE UNIDADES ECONÓMICAS (DENUE)

c. Configuración de estructura de involucrados. En la gestión del DGUT-CH participa una constelación de actores que mantienen un estado latente de conflicto. Destacan propietarios de fincas, propietarios de bares y restaurantes, residentes, grupos de activistas, jóvenes y negocios que han dado un perfil de diversidad sexual, y propietarios de establecimientos comerciales tradicionales. El sector inmobiliario es un actor clave por la inversión en hoteles y edificios de oficinas como la Torre Chapultepec (1991-1995) y varias obras de remodelación de edificios sobre la avenida Chapultepec para instalar bares, cafés, restaurantes y librerías. El proyecto emblemático del nuevo perfil urbano es Horizontes Chapultepec, un complejo de usos mixtos con departamentos de lujo y una zona comercial en sus primeras plantas, cuyo nombre, Las Ramblas, revela la aspiración de transformar el barrio en un centro gastronómico tipo europeo (figura 5). 
FIGURA 4 | Densidad de establecimientos gastronómico-turísticos en el DUGTChapultepec

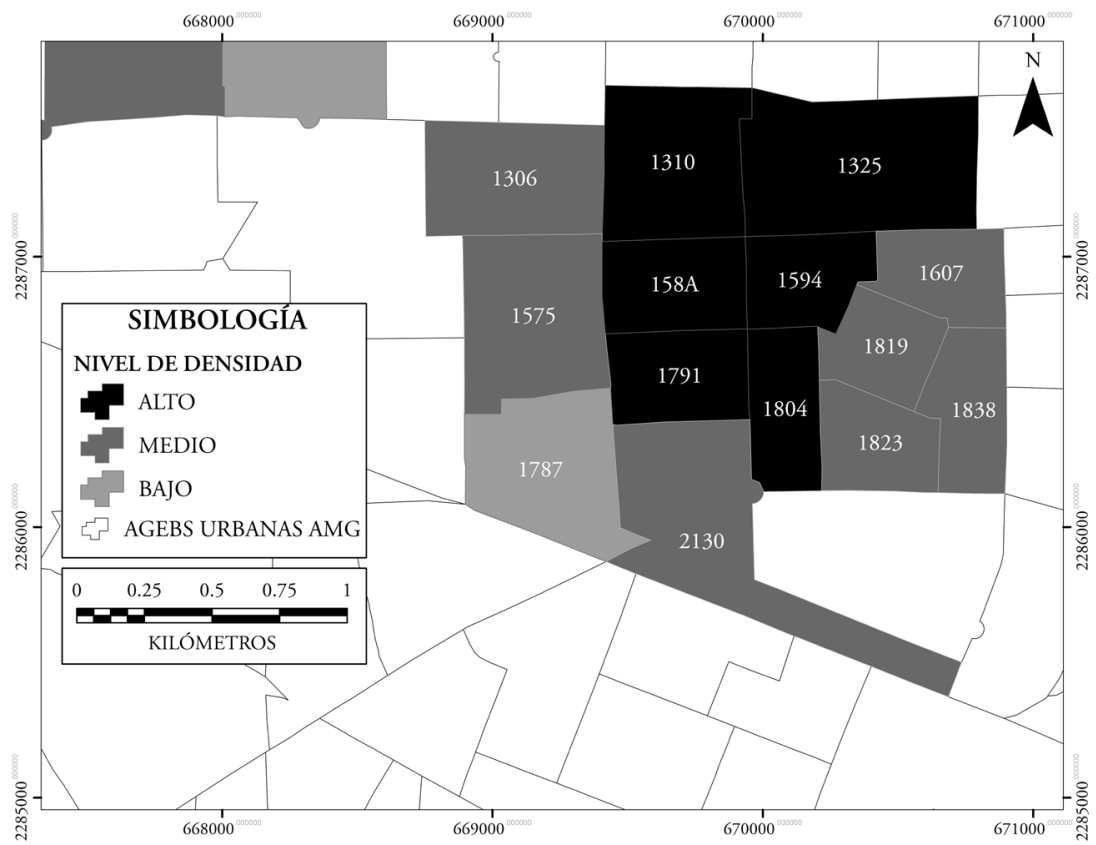

FUENTE ELABORACIÓN PROPIA CON DATOS DE INSTITUTO NACIONAL DE ESTADÍSTICA Y GEOGRAFÍA (INEGi)-DiRECTORIO ESTADÍSTICO NACIONAL DE UNIDADES ECONÓMICAS (DENUE)

Este desarrollo de 296 departamentos obtuvo permisos de construcción en 2006 y fue construido por una empresa de capital español a finales de la primera década de este siglo. Durante años su construcción activó la oposición de los vecinos, quienes criticaron su diseño; presentaron quejas por vibraciones a sus fincas durante la construcción y dańos a fincas con valor patrimonial (Pérez, 2009); expusieron la violación a reglamentos y la insuficiencia de redes de agua; así como daños al entorno habitacional y social (Proceso Jalisco, 2010).

Otro proyecto emblemático es el Mercado México (figura 6), un pabellón de comidas en la planta baja de un viejo edificio remodelado que imita casos de adaptación registrados en sitios como Les Halles en París, la segunda planta del mercado de Florencia, el Chelsea Market de Nueva York o el Old Market Hall (Vanha Kaupahalli) de Helsinki. 
FIgura 5 | Las Ramblas, life sytle mall de Horizontes Chapultepec

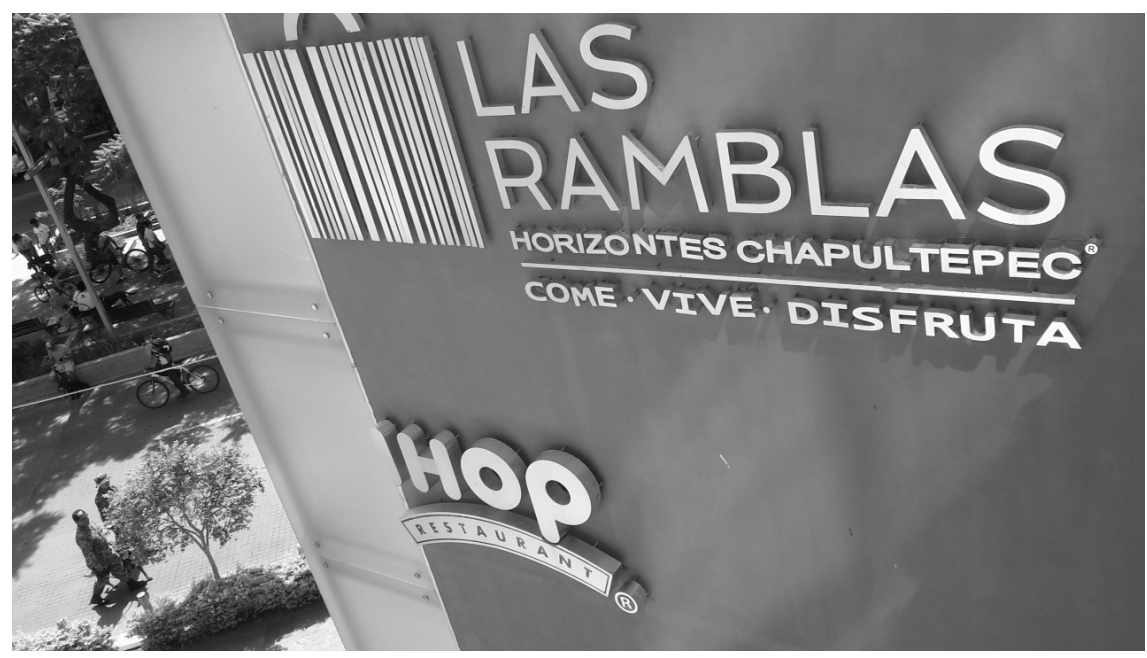

FUENTE FOTOGRAFÍA DE LOS AUTORES

Figura 6 | Mercado México, avenida La Paz y calle Colonias

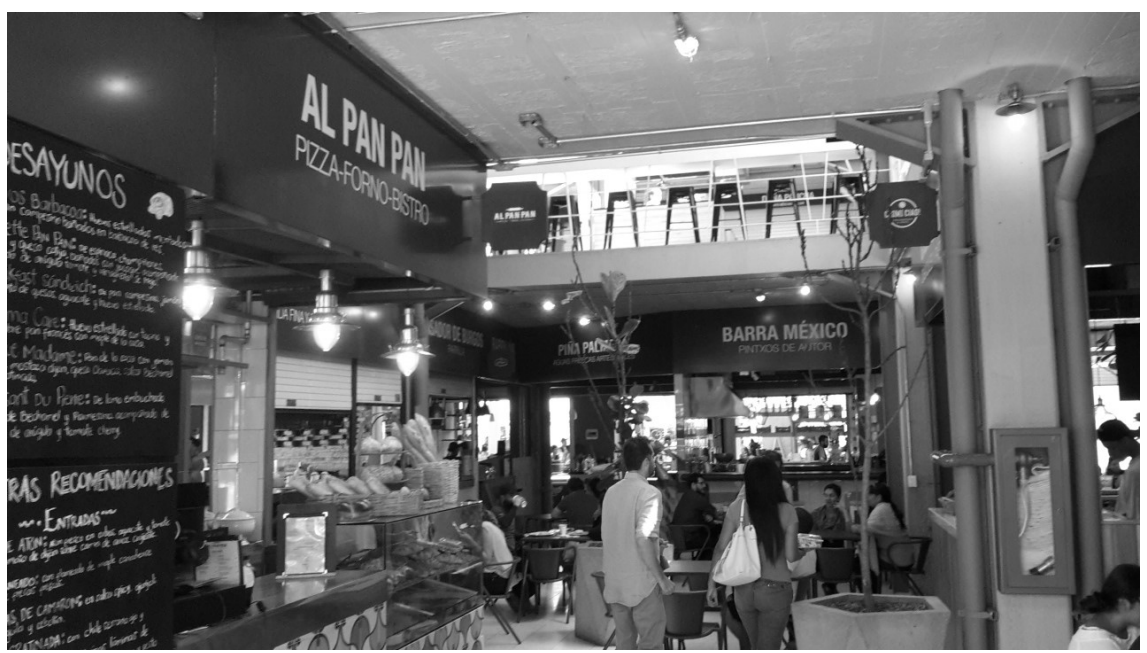

FUENTE FOTOGRAFía DE LOS AUTORES 
d. Conflictos y discursos en torno a las relaciones socioespaciales emergentes. La trasformación de este distrito plantea el reto de consensuar una nueva configuración socioespacial para que la ciudad pueda competir a nivel internacional como destino turístico y centro de negocios con espacios para acomodar nuevos estilos de vida. Los desarrolladores han respondido construyendo edificaciones de corte contemporáneo y minimalista, dirigidas a familias unipersonales, monoparentales o de parejas del mismo sexo, así como el rompimiento de un paisaje dominado por fincas estilo inglés, francés y modernista de mediados del siglo xx y, cada vez menos, familias tradicionales. Paralelamente, ha crecido la cantidad de robos a peatones, automóviles y viviendas a pesar de que la mayoría de los desarrollos de los últimos años poseen servicios de seguridad privada. La inseguridad obstaculiza el objetivo de hacer del DUGT-CH un componente de la experiencia de visitar Guadalajara y de integrarlo en la agenda de visitantes a eventos celebrados en Expo Guadalajara, o a eventos como el festival internacional del mariachi y la charrería, cuyo desfile ha resultado poco exitoso. Su traslado a esta zona le hizo perder el nexo con la tradición de asistir a misa a la catedral y parte de su público, lo cual, según los charros, se debe a que esta es una zona popof, es decir, habitada por gente de alto nivel y pretenciosa. ${ }^{4}$

$\mathrm{Al}$ interior del DUGT-CH hay un proceso de segregación socioespacial. El gasto público se concentra en avenida Chapultepec, tramos de la avenida Vallarta y de las calles López Cotilla y Morelos. Como resultado, se pueden identificar cuatro polígonos con calidades distintas de escenificación de la experiencia turística: el más elegante, en torno al corredor gastronómico López Cotilla, a su vez dividido por tramos según calidad de restaurantes, misma que disminuye al acercarse a Chapultepec; ${ }^{5}$ el polígono norponiente, con varias tiendas de antigüedades y proyectos habitacionales de menor escala que el de Horizontes Chapultepec; y dos polígonos al oriente de Chapultepec, donde se nota una clara disminución de la calidad de remodelaciones de fincas antiguas y nuevas edificaciones, así como una evolución hacia usos comerciales tradicionales.

Las perspectivas de consolidación de este distrito como proveedor de experiencias gastronómico turísticas, en opinión de los involucrados, son contradictorias. Para diversos entrevistados, la avenida Chapultepec se ha degradado rápidamente a una oferta de bares y gastronomía de "alitas y nachos", orientada a jóvenes con bajo poder adquisitivo, y una competitividad basada en precios bajos. La zona enfrenta una amplia variedad de problemas, entre los que se destacan: ${ }^{6}$ comercio informal, falta de seguridad, obras inconclusas, poco mantenimiento, falta de seguimiento a los programas, falta de consolidación de economías de aglomeración entre empresas de calidad (o entre restauranteros y hoteleros), desorganización de proveedores y perspectivas divergentes entre propietarios de negocios y dueños de fincas sobre el futuro de la zona.

\footnotetext{
4 Comunicación personal con un charro durante desfile, 14 de septiembre de 2016.

5 Comunicación personal con restauranteros de la calle López Cotilla, septiembre de 2016.

6 Comunicación personal con restauranteros del distrito, septiembre de 2016.
} 


\section{La aspiración de convertir a Providencia en destino global}

a. Proceso de conversión en distrito gastronómico. El advenimiento de Providencia como distrito urbano gastronómico-turístico es más reciente, pues despegó alrededor de 2005. El distrito se ha conformado en torno a dos secciones: la primera sobre avenida Américas, con un fuerte crecimiento vertical de torres de oficinas, hoteles y condominios; y la segunda, como un corredor hacia el sur formado en las avenidas cuasi paralelas de Rubén Darío y Terranova-Providencia (figura 7). En la sección de avenida Américas se encuentran los hoteles de mayor altura (Fiesta Americana Grand, NH Collection, Aloft y AC-Marriot) y varios de los restaurantes más caros de la zona. Hay una aglomeración de restaurantes en torno a Punto Sao Paulo que data de 2009 (AGEB 0308), pero hay además cuatro AGEB de densidad media, tres de las cuales se ubican a lo largo del corredor Providencia-Terranova-Rubén Darío y una más (0596) en la convergencia Pablo Neruda-avenida Américas y comprende el proyecto de Midtown Jalisco, en construcción desde 2016 (figura 8). El DUGT-P contribuye a la diversificación de la oferta mediante el ensamblaje de las ofertas turismo de negocios-eventos culturales y deportivos-compras y gastronomía, lo cual se facilita por la proximidad de equipamientos deportivos y comerciales.

b. Propuestas de transformación de las administraciones locales. El cambio de la imagen urbana en Providencia ha estado moldeado por la discrecionalidad en la aplicación de las normas urbanas que regulan la densificación y el cambio en los usos de suelo. El Plan Parcial aprobado en la administración 2001-2003 contemplaba un corredor de usos mixto central en avenida Américas, corredores de uso mixto distrital en las avenidas Pablo Neruda, Rubén Darío y Terranova, y una franja de mixto barrial adjunta al corredor Américas en Providencia Norte (H. Ayuntamiento de Guadalajara, 2001-2003c). El gobierno estatal ha apoyado la plusvalía del polígono mediante obras de gran envergadura, como el entubamiento del arroyo de avenida Montevideo, la construcción de un nodo vial subterráneo de la Glorieta Colón, la remodelación de un parque lineal en Pablo Neruda y el equipamiento y uso intensivo de una unidad deportiva para justas internacionales como los Juegos Panamericanos de 2011.

c. Configuración de estructura de involucrados. La constelación de actores que debaten la transformación del DUGT-P es relativamente menos amplia que en Chapultepec, pues está dominada por el gobierno local, grandes desarrolladores inmobiliarios y vecinos opuestos a los cambios de uso de suelo y la densificación. Los conflictos entre esa triada de involucrados no han impedido la creación de un paisaje de bancos y otras empresas del sector servicios, torres de condominio para el segmento de altos ingresos y una gran cantidad de establecimientos de alimentos y bebidas, o el desarrollo de complejos de uso mixto como Punto Sao Paulo, que alberga oficinas corporativas de HSBC y Tequila Herradura, un complejo de cines platino de la cadena Cinemex, un casino y una tienda de Apple. 
FIgURA 7 Distribución de establecimientos gastronómico-turísticos en el DUGT-Providencia

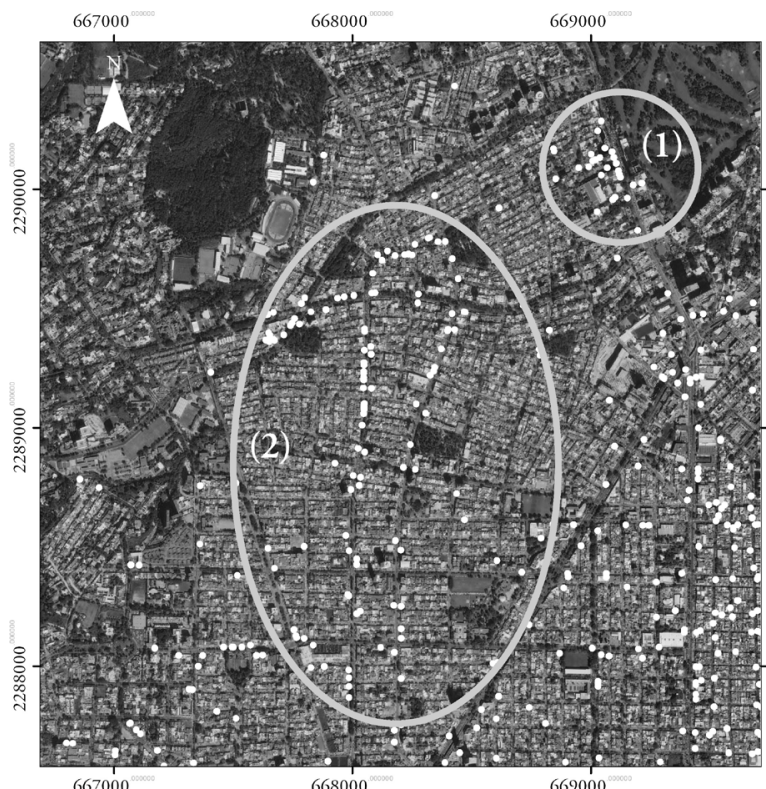

(1) Punto Sao Paulo

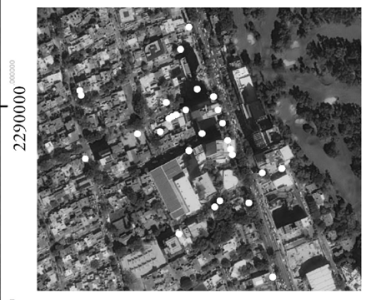

(2) Corredor Rubén Darío/Terranova/ $\stackrel{\sim}{\sim}$ Providencia

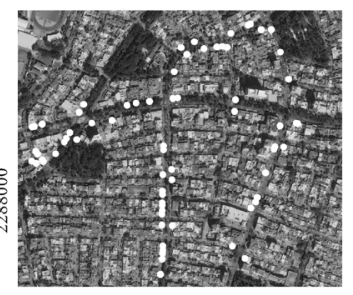

FUENTE ELABORACIÓN PROPIA CON DATOS DE INSTITUTO NACIONAL DE ESTADÍSTICA Y GEOGRAFÍA (INEGI), DIRECTORIO ESTADÍSTICO NACIONAL DE UNIDADES ECONÓMICAS (DENUE)

FIGURA 8 | Densidad de establecimientos gastronómico-turísticos en el DUGTProvidencia

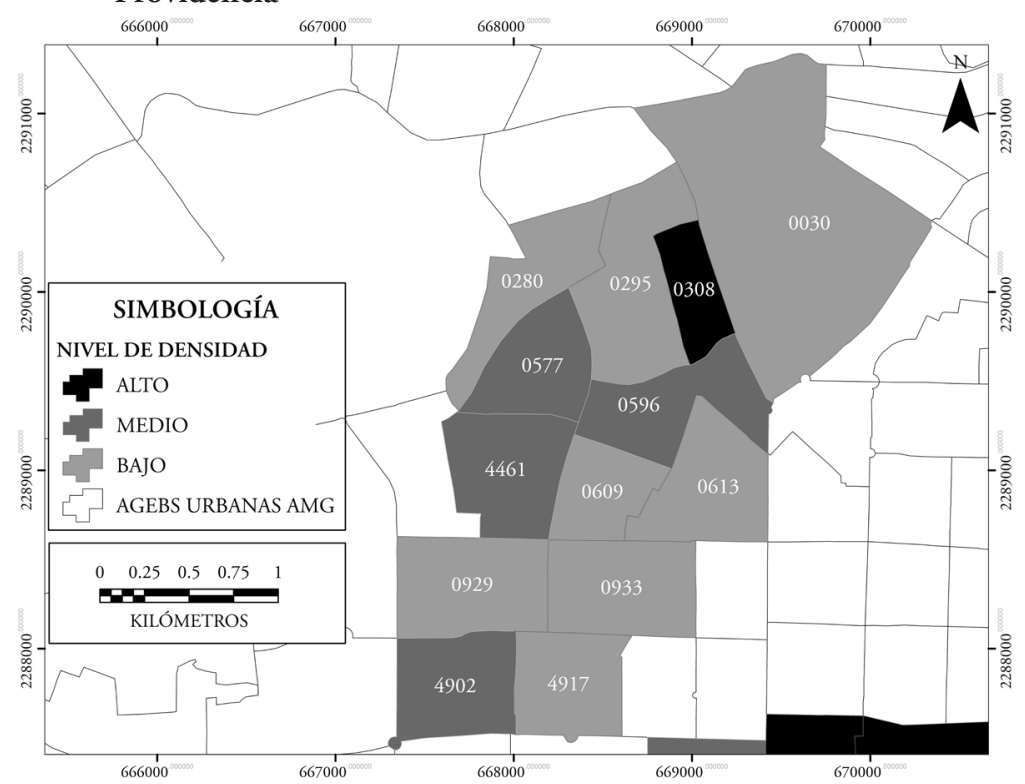

FUENTE ELABORACIÓN PROPIA CON DATOS DE INSTITUTO NACIONAL DE ESTADÍSTICA Y GEOGRAFÍA (INEGI), DIRECTORIO ESTADÍSTICO NACIONAL DE UNIDADES ECONÓMICAS (DENUE) 
d. Conflictos y discursos en torno a las relaciones socioespaciales emergentes. El proceso de escenificación para fines turísticos y gastronómicos de este distrito pasa por la emergencia de soluciones urbanísticas y el uso fluido de las nociones de espacio público y privado, uso habitacional o sustentabilidad. El nuevo paisaje urbano simboliza la existencia de nuevas relaciones de poder en las mesas de decisión sobre desarrollo urbano. El sello de la firma New York Life sobre un nuevo edificio construido en Américas 1500, funge como metáfora de la nueva correlación de fuerzas y de la aspiración de contar con una urbe global (figura 9), pero también como preludio de una ruta de cambio urbano que se consolidará con el centro comercial Midtown Jalisco, que se construye sobre terrenos de lo que fue el Club Deportivo Guadalajara (Chivas).

La calle Sao Paulo ejemplifica, a su vez, un urbanismo caracterizado por la revalorización del espacio urbano con proyectos construidos sobre las mansiones de algunas familias fundadoras de este suburbio. Punto Sao Paulo, con el hotel NH, detonó una ola expansiva de servicios de gastronomía y turismo porque vino a complementar la oferta de hotelería iniciada con la construcción del hotel Fiesta Americana Grand, y el crecimiento del sector financiero iniciado tres décadas antes. Le siguieron el hotel Aloft de la cadena Starwood, y el hotel AC Marriot, así como nuevos centros gastro-comerciales, como Punto Amazonas y Fusión Galerías, ubicados en un radio de tres cuadras en avenida Providencia.

En la calle Sao Paulo se integran elementos arquitectónicos modernos y tradicionales para un turismo que procura experiencias propias de la aldea global. La Casa de los Platos conserva partes de un muro con platos del mundo coleccionados por los propietarios de la residencia sobre la cual se construyó este restaurante. En él se sirven platillos definidos como "cocina de hacienda", una oferta que contrasta con la de restaurantes vecinos con un enfoque gourmet internacional.

En Providencia no se han multiplicado los eventos de tipo cultural o recreativo. Sin embargo, en 2015, avenida Américas volvió a ser parte del recorrido de la Virgen de Zapopan a su basílica, un evento anual que atrae a más de un millón de peregrinos. La Secretaría de Turismo estatal ha instalado anuncios en los que destaca el perfil financiero y de altos ingresos de la zona y su importancia para la economía de la metrópoli. En 2015 lanzó una campaña por el aniversario de la ciudad expresando el orgullo que generan los restaurantes de Providencia, lo cual motivó el enojo de los vecinos por ignorar sus inconveniencias (Carapia, 2015). En mayo de 2017, la calle Sao Paulo se convirtió en escenario cultural para un concierto al aire libre patrocinado por el gobierno estatal como parte del Festival Cultural de Mayo.

El cambio registrado en Providencia y sus proyectos tipo life style mall, con seguridad privada, han originado múltiples conflictos. La queja más recurrente de los vecinos se refiere a violaciones de los usos de suelo, pero el listado de asuntos en debate incluye el incumplimiento del código urbano, altura excesiva, reducción de asoleamiento, falta de dictámenes de factibilidad hidrológica, impactos ambientales, problemas geológicos, congestionamiento vial, inseguridad, basura, falta de cajones de estacionamiento, invasión de servidumbre, ruido, invasión de cocheras, choques y actos de inmoralidad en la vía pública. 
FIGURA 9 | Edificios y usos de suelo con aspiración global en el DUGT-Providencia

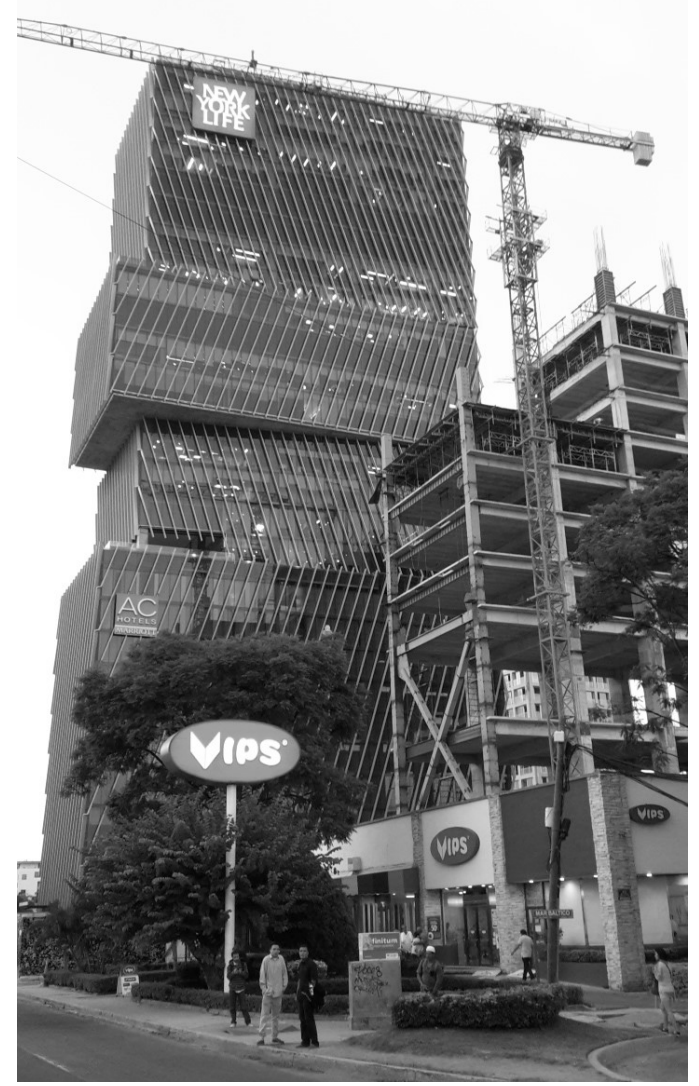

FUENTE FOTOGRAFía DE LOS AUTORES

El gobierno estatal ha respondido a los problemas viales interviniendo una zona de once manzanas para regular el congestionamiento vial provocado por la concentración de restaurantes, hoteles y oficinas. ${ }^{7}$

\section{Implicaciones para gestión urbana}

La consolidación de los DUGT como productos turísticos es útil para revalorizar zonas urbanas tradicionales e impulsar la competitividad de una ciudad, pero dicha estrategia demanda la participación de múltiples involucrados (Laesser \& Beritelli, 2013). El proceso observado en Chapultepec y Providencia tiene diversas implicaciones para la gestión urbana negociada, entre ellas, las que se presentan a continuación.

7 La intervención abarca regulación de hidrantes, horarios para repartir mercancías, uso de valet parking y semáforos (“Ordenarán y fijarán...”, 2016). 
La escenificación de un DUGT ubicado en una zona habitacional de altos ingresos es una variante importante a los procesos de regentrificación o supergentrificación reportados en la literatura especializada para ciudades como París (Gravari-Barbas, 2017), Londres (Butler \& Lees, 2006) y Nueva York (Lees, 2003). Los dos casos muestran la disposición de los gobiernos locales a responder favorablemente a las presiones del capital inmobiliario para apropiarse los beneficios del turismo en busca de experiencias. Los cambios de partido político en las administraciones locales no han interrumpido la lógica pro crecimiento o el discurso de la competitividad turística de la ciudad.

La creación de experiencias gastronómico-turísticas demanda aglomeraciones con oferta diversificada. De acuerdo con Meethan (2015), no es lo mismo viajar para tener una experiencia culinaria que tener una experiencia culinaria cuando se viaja. Un destino turístico competitivo debe ofrecer a los visitantes diversidad de opciones gastronómicas y hoteleras, servicios complementarios y espacios urbanos abiertos a la exploración activa.

En Chapultepec y Providencia se han multiplicado los problemas de seguridad, movilidad y segregación interna. En Chapultepec, incluso, hace falta oferta hotelera, lo que ha sido detectado por cadenas internacionales para abrir nuevos establecimientos. ${ }^{8}$ En Providencia hace falta oferta complementaria a los hoteles y restaurantes de la zona, y existe la percepción de que el corredor Rubén DaríoTerranova no logra consolidarse por errores en la mezcla de lo ofrecido. ${ }^{9}$ También faltan mejores opciones de transporte, mejor regulación y transparencia en el otorgamiento de licencias y permisos para construir o abrir negocios. ${ }^{10} \mathrm{La}$ persistencia del tema de inseguridad en los debates públicos sobre la transformación de estos distritos sugiere que la proliferación de guardias privadas en edificios públicos y privados no es suficiente para atender las condiciones situacionales que originan la comisión del delito si no se tienen estrategias preventivas.

Los conflictos demandan negociaciones multilaterales y sensibilidad al contexto de cada distrito. En ambos casos hay un escenario de diversidad de involucrados con poca experiencia y disposición a negociar. Un análisis de notas hemerográficas permite identificar como actores clave a desarrolladores inmobiliarios, propietarios tradicionales de fincas de uso habitacional, nuevos residentes de condominios verticales, consumidores de los diversos servicios ofrecidos en dichas zonas (aquí se pueden distinguir distintos segmentos si se toma en cuenta nivel de ingreso, edad, estilo de vida y género, entre otros), transportistas, cuerpos de seguridad, tomadores de decisión en el ámbito municipal y estatal, visitantes a las zonas, así como ONG interesadas en temas de movilidad, infraestructura y respeto del patrimonio construido.

9 Comunicación personal con empleado de hotel AC Marriot, con empleo previo en bares y restaurantes de Providencia, junio de 2016.

10 Comunicación personal con gestor de permisos para restaurantes, marzo de 2016. 
Una diferencia notable entre los dos casos es que mientras en Chapultepec abundan las controversias en torno a imagen urbana y patrimonio edificado, en Providencia prevalecen las quejas sobre impactos de la transformación urbana en el estilo de vida suburbano, el ruido, inseguridad e impacto sobre las infraestructuras.

La presencia de conflictos significa que para competir en los mercados nacional e internacional de turismo, las ciudades necesitan contar con procesos de negociación abiertos a la participación ciudadana basados en análisis empíricos serios. En los casos estudiados prevalece el debate sin mayor información sobre las consecuencias de seguir una opción o cancelar otra. El debate sobre las implicaciones del desarrollo vertical y de usos mixtos al estilo de Horizontes Chapultepec, Punto Sao Paulo y Midtown Jalisco, en páginas como Skycrapercity.com, adopta una vertiente discursiva celebratoria de foristas y desarrolladores, quienes piensan que entre más alto mejor, ${ }^{11}$ mientras que otros estigmatizan el crecimiento vertical por considerarlo ajeno al patrón de desarrollo metropolitano de Guadalajara.

Se necesita mayor coordinación público-privada e intergubernamental para atender problemas de transporte colectivo, seguridad e imagen urbana, o para fortalecer la imagen de los distritos en forma incluyente y preservar el patrimonio existente. En Providencia, la proliferación de edificios de mayor altura -entre 20 y 25 pisos- y sus diseños sin mayores aspiraciones arquitectónicas resultan adversos al objetivo de consolidar un paisaje urbano distintivo.

La falta de visión en la regulación urbana y en planes urbanos genera conflictos innecesarios. Los gobernantes locales suelen aprobar planes incapaces de acomodar las demandas del mercado inmobiliario, lo cual incrementa la posibilidad de corrupción. En los procesos de negociación durante el diseño y la aprobación de planes urbanos y en la aprobación de licencias prevalece cierto grado de discrecionalidad. Por ello, los vecinos insisten en que la transformación de los DUGT viola los planes parciales y representa un costo que ellos deben asumir sin esperar beneficios.

\section{Conclusiones}

La comparación de los DUgT Chapultepec y Providencia muestra la importancia de contextualizar las trayectorias temporales y su impacto en las constelaciones de actores que participan en la gestión urbana y turística. La dimensión temporal del cambio induce variaciones en los discursos usados en el debate público sobre la transformación de un distrito. La existencia de antecedentes comerciales previos amplía la diversidad de actores y la dificultad para lograr acuerdos colectivos. Hay más voces y actores mejor organizados discutiendo el caso Chapultepec que el caso Providencia. Tal vez por eso el cambio en Providencia es más profundo en polígonos específicos.

El valor histórico patrimonial en Chapultepec es un asidero para los opositores al cambio de este distrito, pero no lo ha detenido. Los críticos insisten en el tema de identidad barrial, imagen urbana y seguridad, mientras que en Providencia las

11 Wowdalajarian, un usuario de esta página, comenta respecto a Midtown Jalisco: "Que emoción, POR FIN!!! Súper elegante el MTj y un muy buen replanteamiento de Sordo Madaleno, se nota su evolución de Andares a MTJ me gusta, me gusta”. 
quejas destacan la preservación de nociones de exclusividad, respeto a un estilo de vida suburbano y deficiencias en la infraestructura disponible.

El gobierno local ha respondido diferenciadamente para defender una misma estrategia de promoción del capital inmobiliario, revalorización del espacio urbano y desarrollo de productos turísticos para competir globalmente. En Chapultepec se impulsa una zona de desarrollo urbano con opciones peatonalizadas y transporte no motorizado. En Providencia se impulsa una zona de alta densidad servida principalmente por el automóvil, con espacios para desarrollos de comercios y oficinas de alta densidad. Los casos estudiados cuestionan la pertinencia de planes comprensivos de regulación de uso de suelo.

Hacen falta mejores procesos participativos para debatir planes y proyectos y mejorar la comunicación de involucrados. En Chapultepec, hay esfuerzos colectivos entre restauranteros que no incluyen a los dueños de las fincas. En Providencia, la movilización vecinal es baja y mal organizada. Hace falta crear procesos de negociación transparentes que den certidumbre jurídica y social a los procesos de cambio urbano. La aprobación de proyectos que inducen cambios en los distritos estudiados suele ocurrir en sesiones del ayuntamiento que no muestran cómo se construye el posicionamiento de los regidores. La consulta pública no avanza hacia consensos estables, lo cual da lugar a cabildeo y arreglos informales en los que participan emprendedores de política pública.

La conformación de los DUGT Chapultepec y Providencia abona al problema de desigualdad urbana en Guadalajara. El debate público elitista sobre esta transformación reduce las acciones dirigidas a resolver el fondo de ese problema. El debate en estos distritos termina por atraer a ellos recursos públicos que reducen lo disponible para intervenir en otros procesos urbanos y necesidades sociales, pero la escenificación del espacio urbano no se hace sobre la noción de comunidades urbanas y desalienta la participación democrática más amplia en la metrópoli.

\section{Referencias bibliográficas}

Acercan más servicios a la zona financiera (1995, 8 de mayo). El Informador, p. 6B. hemeroteca. informador.com.mx

Arnold, T. (2016, 19 de abril). Carlsbad Village master plan a disaster. http://bit.ly/2uPTvUr

Barrère, C., Quentin, B. \& Chossat, V. (2012). Food gastronomy and cultural commons. En E. Bertacchini G. Bravo, M. Marrelli \& W. Santagata (eds.), Cultural commons: A new perspective on the production and evolution of cultures (pp. 129-151). Northampton: Edward Elgar.

Benur, A. \& Bramwell, B. (2015). Tourism product development and product diversification in destinations. Tourism Management, 50, 213-224. https://doi.org/10.1016/j. tourman.2015.02.005 
Boyd, S. (2015). The 'past' and 'present' of food tourism. En I. Yeoman, U. McMahon-Beattie, K. Fields, J. N. Albrecht \& K. Meethan (eds.), The future of food tourism: Foodies, experiences, exclusivity, visions and political capital (pp. 11-22). Bristol: Channel View Publications.

Butler, T. \& Lees, L. (2006). Super-gentrification in Barnsbury, London: Globalization and gentrifying global elites at the neighbourhood level. Transactions of the Institute of British Geographers, 31(4), 467-487. https://doi.org/10.1111/j.1475-5661.2006.00220.x

Byrd, E. (2007). Stakeholders in sustainable tourism development and their roles: Applying stakeholder theory to sustainable tourism development. Tourism Review, 62(2), 6-13. https://doi.org/10.1108/16605370780000309

Carapia, F. (2015, 23 de febrero). Enoja spot a vecinos de providencia. Mural. http://bit. ly/1MMPiFw

Corvo, P. (2015). Food culture, consumption and society. Nueva York: Palgrave MacMillan.

Crespi, M. \& Domínguez, M. (2013). Urban strategies in tourist places. Cases of Madrid and Barcelona. ROTUR, Revista de Ocio y Turismo, 6(1), 13-33. https://doi.org/10.17979/ rotur.2013.6.1.1270

Della Lucia, M., Trunfio, M. \& Go, F. (2016). Does the culture of context matter in urban regeneration processes? En M. Alvarez, A. Yüksel \& F. Go (eds.), Heritage tourism destinations: Preservation, communication and development (pp. 11-21). Oxfordshire: Cabi.

Ellis, S. \& Sheridan, L. (2014). A critical reflection on the role of stakeholders in sustainable tourism development in least-developed countries. Tourism Planning \& Development, 11(4), 467-471. http://dx.doi.org/10.1080/21568316.2014.894558

En el Centro histórico habilitarán calles de "tráfico tranquilizado" (2000, 29 de octubre). El Informador. hemeroteca.informador.com.mx

Fox, K. (2010). Tourism gentrification: The case of New Orleans' Vieux Carre (French Quarter). En J. Brown-Saracino (Ed.), The gentrification debates: A reader (pp. 146-173). Nueva York: Routledge.

Gibson, D. (2012). Commercial space tourism: Impediments to industrial development and strategic communication solutions. Oak Park, Ill: Bentham eBooks. http://dx.doi.org/1 $0.2174 / 97816080523941120101$

Glass, R. (2010). Aspects of change. En J. Brown-Saracino (ed.), The gentrification debates. A reader (pp. 19-30). New York: Routledge.

Gordin, V. \& Trabskaya, J. (2013). The role of gastronomic brands in tourist destination promotion: The case of St. Petersburg. Place Branding and Public Diplomacy, 9(3), 189-201. https://doi.org/10.1057/pb.2013.23

Gravari-Barbas, M. (2017). Super-gentrification and tourismification in Le Marais, Paris. En M. Gravari-Barbas \& S. Guinand (eds.), Tourism gentrification in contemporary metropolises. International perspectives (pp. 299-328). Londres: Routledge.

Gravari-Barbas, M. \& Jacquot, S. (2017). No conflict? Discourses and management of tourismrelated tensions in Paris. En C. Colomb \& J. Novy (eds.), Protest and resistance in the tourist city (pp. 31-51). Nueva York: Routledge.

H. Ayuntamiento de Guadalajara (2001-2003a). Plan parcial de desarrollo urbano, Distrito urbano "Zona 1", Subdistrito urbano 5 "Americana-Moderna". transparencia.guadalajara. gob.mx 
H. Ayuntamiento de Guadalajara (2001-2003b). Plan parcial de desarrollo urbano, Distrito urbano "Zona 1", Subdistrito urbano 6 "Santa Teresita". transparencia.guadalajara.gob.mx

H. Ayuntamiento de Guadalajara (2001-2003c). Plan parcial de desarrollo urbano, Distrito urbano "Zona 2 Minerva" Subdistrito urbano 6 "Providencia Norte". transparencia. guadalajara.gob.mx

H. Ayuntamiento de Guadalajara (2016, 14 de abril). Plan municipal de desarrollo de Guadalajara 500/visión 2042. Gaceta Municipal. transparencia.guadalajara.gob.mx.

Hall, C. \& Gössling, S. (2016). From food tourism and regional development, to food, tourism and regional development: Themes and issues in contemporary foodscapes. En C. Hall \& S. Gössling (eds.), Food tourism and regional development: Networks, products and trajectories (pp. 3-58). Nueva York: Routledge.

Instituto Nacional de Estadística y Geografía (Inegi). (2011). XIII Censo general de población y vivienda 2010. http://www.beta.inegi.org.mx/proyectos/ccpv/2010/

Instituto Nacional de Estadística y Geografía (Inegi), Directorio Estadístico Nacional de Unidades Económicas (Denue). (2016, enero). http://www.beta.inegi.org.mx/app/ mapa/denue/

Janoschka, M., Sequera, J. \& Salinas, L. (2014). Gentrificación en España y América Latina. Un diálogo crítico. Revista de Geografia Norte Grande, (58), 7-40. http://dx.doi. org/10.4067/S0718-34022014000200002

Jensen-Verbeke, M. \& Govers, R. (2009). Brussels: A multilayered capital city. En R. Maitland \& B. Ritchie (eds.), City tourism: National capital perspectives (pp. 142-158). Oxfordshire: Cabi.

Kong, L. \& Sinhaa, V. (2016). Theorizing contemporary foodscapes: Conceptual and empirical insights from Singapore. En L. King \& V. Sinha (eds.), Food, foodways and foodscapes: Culture, community and consumption in post-colonial Singapore (pp. 1-22). Singapur: World Scientific.

Kowalczyk, A. (2014). From street food to food districts - gastronomy services and culinary tourism in an urban space. Turystyka Kuturowa, (9), 136-160. http://bit.ly/2gJ8zi0

Laesser, C. \& Beritelli, P. (2013). St. Gallen consensus on destination management. Journal of Destination Marketing \& Management, 2(1), 46-49. https://doi.org/10.1016/j. jdmm.2012.11.003

Lafayette, la joya patrimonial de Guadalajara (2011, 9 de agosto). El Informador. http://bit. ly/2kSRS8p

Lazzeretti, L. \& Petrillo, C. (eds.).(2006). Tourism local systems and networking. Boston: Elsevier.

Leal, M. (2015). Related strategies to promote gastronomy in geographically disadvantaged areas. A comparative analysis of Catalonia and Scotland.Via@ Tourism Review, 2(8). http://viatourismreview.com/2015/10/varia-art2/,

Lees, L. (2000). A reappraisal of gentrification: Towards a 'geography of gentrification'. Progress in Human Geography, 24(3), 389-408. https://doi.org/10.1191/030913200701540483

Lees. L. (2003). Super-gentrification: The case of Brooklyn Heights, New York City. Urban Studies, 40(12), 2487-2509. https://doi.org/10.1080/0042098032000136174

Lew, A. (2007). Pedestrian shopping streets and urban tourism in the restructuring of the Chinese city. En A. Church \& T. Coles (Eds.), Tourism, power and space (pp. 150-170). Londres: Routledge. 
López, E. (2001). La cuadrícula en el desarrollo de la ciudad hispanoamericana, Guadalajara, México. Guadalajara: Universidad de Guadalajara, Instituto de Estudios Superiores de Occidente.

Mariscal, M. (2015, 4 de enero). Apuesta Guadalajara a los corredores gastronómicos. Crónica Jalisco. http://www.cronicajalisco.com/notas/2015/33893.html.

Medeiros de Araujo, I. \& Bramwell, B. (2000). Stakeholder assessment and collaborative tourism planning: The case of Brazil's Costa Dourada project. En B. Bramwell \& B. Lane (eds.), Tourism collaboration and partnerships: politics, practice and sustainability (pp. 272-294). Buffalo, NY: Chanel View Publications.

Meethan, K. (2015). Making the difference: The experience economy and the future of regional food tourism. En I. Yeoman, U. McMahon-Beattie, K. Fields, J. N. Albrecht \& K. Meethan (eds.), The future of food tourism: Foodies, experiences, exclusivity, visions and political capital (pp. 114-126). Bristol: Channel View Publications.

Modica, P. (2015). Sustainable tourism management and monitoring. Destination, business and stakeholder perspectives. Milan: FrancoAngeli.

Okumus, B., Okumus, F. \& McKercher, B. (2007). Incorporating local and international cuisines in the marketing of tourism destinations: The cases of Hong Kong and Turkey. Tourism Management, 28(1), 253-261. https://doi.org/10.1016/j.tourman.2005.12.020

Ordenarán y fijarán horario de carga y descarga en la calle de Sao Paulo (2016, 11 de septiembre). El Informador. http://bit.ly/2cmZ2Ky

Pérez, I. (2009, 18 de agosto). Critican reactivación de Horizontes Chapultepec. Crónica de Sociales. https://cronicadesociales.org/2009/08/18/critican-reactivacion-de-horizontes -chapultepec/

Perham, S. (2012). Market place: Food quarters, design and urban renewal in London. Newcastle upon Tyne: Cambridge Scholars Publishing.

Pine, J. \& Gilmore, J. (1999). The experience economy: Work is theatre and every business a stage. Boston: Harvard Business School Press.

Proceso Jalisco (2010, 31 de enero). El millonario proyecto panista. Proceso Jalisco, (273), 1011. http://www.proceso.com.mx/83491/el-millonario-proyecto-panista.

Richards, G. (2002). Gastronomy: An essential ingredient in tourism production and consumption? En A.-M. Hjalager \& G. Richards (eds.), Tourism and gastronomy (pp. 3-20). Nueva York: Routledge.

Rogerson, C. (2006). Tourism policy, local economic development and South African cities. En U. Pillay, R. Tomlinson \& J. Du Toit (eds.), Democracy and delivery: Urban policy in South Africa (pp. 230-251). Cape Town: HSRC Press.

Ruzzier, M. \& Petek, N. (2014). The importance of diverse stakeholders in place branding: The case of "I feel Slovenia". En R. Baggio, W. Czakon \& M. Mariani (eds.), Managing tourism in a changing world: Issues and cases (pp. 49-60). Nueva York: Routledge.

Secretaría de Desarrollo Social (Sedesol), Consejo Nacional de Población (Conapo), Instituto Nacional de Estadística y Geografía (Inegi) (2012). Delimitación de las zonas metropolitanas de México 2010. http://bit.ly/2b7LItA

Smith, N. (1996). The new urban frontier: Gentrification and the revanchist city. Nueva York: Routledge.

Tallon, A. (2013). Urban regeneration in the UK ( $2^{a}$ ed.). Nueva York: Routledge. 
Thomasz, A. (2016). Los nuevos distritos creativos de la Ciudad de Buenos Aires: la conversión del barrio de La Boca en el "Distrito de las Artes". EURE, 42(126), 145-167. http:// dx.doi.org/10.4067/S0250-71612016000200007

Torre Chapultepec, Ícono de la modernidad de Guadalajara (2016, 10 de octubre). Crónica Jalisco. http://www.cronicajalisco.com/notas/2015/42041.html

Van der Aa, B., Groote, P. \& Huigen, P. (2004). World Heritage as NIMby? The case of the Dutch part of the Wadden Sea. Current Issues in Tourism, 7(4-5), 291-302. http:// dx.doi.org/10.1080/13683500408667986

Verduzco, B. (2013). Una utopía urbana (im)posible, la negociación infinita de planes urbanos y prosperidad. Guadalajara: Universidad de Guadalajara.

Vergara-Constela, C. \& Casellas, A. (2016). Políticas estatales y transformación urbana: ¿hacia un proceso de gentrificación en Valparaiso, Chile? EURE, 42(126), 123-144. http:// dx.doi.org/10.4067/S0250-71612016000200006

Wilson, J. \& Tallon, A. (2012). Geographies of gentrification and tourism. En J. Wilson (Ed.), The Routledge handbook of tourism geographies (pp. 103-112). Nueva York: Routledge.

Wowdalajarian. (2014, 9 de octubre). Proyecto Providencia Midtown Jalisco [Mensaje en un blog]. http://www.skyscrapercity.com/showthread.php?t=1760672 